\title{
A prospective randomised clinical trial of one bis-GMA-based and two ormocer-based composite restorative systems in class II cavities: Three-year results
}

\author{
P. Bottenberg ${ }^{a, *}$, M. Alaerts $^{a}$, F. Keulemans ${ }^{a, b}$ \\ ${ }^{a}$ Department of Restorative Dentistry, Vrije Universiteit Brussel, Laarbeeklaan 103, B-1090 Brussels, Belgium \\ ${ }^{\mathrm{b}}$ Department of Dental Materials Science, Academic Centre for Dentistry Amsterdam (ACTA), Universiteit van Amsterdam \\ and Vrije Universiteit; Louwesweg 1, 1066 EA Amsterdam, The Netherlands
}

\section{A R T I C L E I N F O}

\section{Article history:}

Received 12 May 2006

Received in revised form

26 June 2006

Accepted 7 July 2006

\section{Keywords:}

Composite resins

Ormocer

USPHS criteria

Clinical trial

\begin{abstract}
A B S T R A C T
Objectives: Ormocer composites, consisting of a silicon-based polymer, have been developed recently as a tooth-coloured restorative material. The purpose of this prospective randomised clinical trial was to evaluate the performance of two small-particle hybrid ormocerbased restorative systems (AD, Admira/Admira Bond, VOCO; DE, Definite/Etch \& Prime 3.0, Dentsply) and one small-particle hybrid bis-GMA-based composite restorative system (TC, Tetric-Ceram/Syntac, Ivoclar-Vivadent) in occlusal stress-bearing restorations.

Methods: One hundred and twenty-eight occlusal-proximal restorations (44 AD, $43 \mathrm{DE}$ and $41 \mathrm{TC}$ ) were placed according to the manufacturer's instructions in thirty-two adult patients. Their clinical performance was scored according to the USPHS criteria and evaluation of bite-wing radiographs.

Results: After 3 years, four AD, five DE and four TC restorations had failed due to fracture or marginal gap formation. Surface roughness improved significantly when compared to the baseline in AD and TC (Friedman test, $p<0.05$ ) during the first year but returned to baseline values after 3 years. DE had a significant tendency towards discolouration $(p<0.05)$. Bitewing radiographs showed two $\mathrm{AD}$ and one $\mathrm{TC}$ restorations with internal porosities. ANOVA showed that larger restorations ( $\geq 3$ surfaces) showed significantly more degradation than smaller ones.

Conclusions: In a group of class II restorations, there was no significant difference in failures after 3 years between ormocer-based and bis-GMA-based restorative systems.
\end{abstract}

(C) 2006 Elsevier Ltd. All rights reserved.

\section{Introduction}

Composite resins have gained widespread acceptance even in cavities exposed to occlusal load. Concerns about appearance and the mercury content of amalgam restorations have increased the demands for tooth-coloured restorations even in posterior teeth. However, persistent problems are polymerization shrinkage leading to gap formation and possibly secondary caries, wear with loss of anatomy and disturbance of occlusal relationships and degradation leading to fracture. According to clinical studies of longevity and failure rate, composite restorations in (pre)molar teeth exhibited a lower useful life period in comparison to amalgam restorations. Collins et al. ${ }^{1}$ reported, after 8 years of observation, a two to three times higher failure rate for composite restorations than for amalgam restorations. While progress was undoubtedly

\footnotetext{
* Corresponding author. Tel.: +32 247749 55; fax: +32 24774942 .

E-mail address: pbottenb@vub.ac.be (P. Bottenberg). 
made in the composition of fillers, the composition of the polymer matrix remained principally unchanged since the introduction of bis-GMA resin by Bowen in the early 1960s. Attempts were made to reduce polymerization shrinkage and wear susceptibility but this did not lead to products that reached clinical practice. Recently, ormocers were developed as suitable as a dental restorative material. ${ }^{2}$ Ormocers (organically modified ceramics) consist of a long "backbone" of silicon instead of carbon, on which carbon-carbon doublebond-containing side-chains are grafted. These allow polymerization using conventional photoinitiators known in restorative dentistry. The larger size of the monomer molecule that can reduce polymerization shrinkage, wear and reduce leaching of monomers makes ormocers interesting materials as a matrix for resin composites. This may be the reason for their increased biocompatibility. ${ }^{3,4}$ In laboratory studies not all of these claims have been substantiated. ${ }^{5}$ Also, some clinical evidence cast doubts on the superiority of ormocer restoratives. ${ }^{6}$ But none of the available ormocer restoratives have been evaluated in a comparative clinical study. Therefore, the aim of the study was to evaluate the clinical performance of two newly introduced ormocer-containing micro particle hybrid composite restorative systems (AD: Admira/Admira Bond, VOCO, Cuxhaven, Germany and DE: Definite/Etch \& Prime 3.0, Degussa, Hanau, Germany, now made by Dentsply) and to compare it to that of a conventional fine-particle hybrid composite restorative system (TC: TetricCeram/Syntac Sprint, Ivoclar-Vivadent, Schaan, Liechtenstein). The working hypothesis was that material properties had an influence on the clinical performance of the restorative systems.

\section{Materials and methods}

\subsection{Patient selection}

Following positive review by the medical faculty ethics committee, adult patients were selected among the routine polyclinic patients from the dental school clinic and volunteers from staff and students and their family. To be included in the study, they needed to have had several primary carious lesions or defective restorations, including at least one proximal, and the occlusal surface on teeth having an antagonist. Patients needed to be able to attend the recall examinations. Their caries risk was to be low: only proximal lesions that had remained undetected (probably for some years) by previous visual inspection by external dentists were admitted to the study.
Patients having smooth-surface lesions and high amounts of visible plaque were excluded. Before the treatment, bite-wing radiographs were taken. Written informed consent was obtained after giving oral information about the goal and method of the study. Eventually, 32 patients ( 14 male, 18 female) were included in the study. Their age at the start of the study ranged from 19 to 56 years (median: 38 years).

The randomisation was performed by noting each tooth to be restored (FDI 2-digit code) on one paper and the type of restorative system on a second. First, a tooth number was drawn blindly. Subsequently, a restorative system was allocated to this tooth by blind drawing. This procedure was repeated if more than three restorations had to be placed. If another patient had more than three restorations, the paper of the supernumerary restorative system was removed from the set. 135 multi-surface occluso-proximal restorations (44 AD, 43 $\mathrm{DE}$ and $41 \mathrm{TC}$ ) were placed. $26 \mathrm{AD}$ restorations were placed in premolars, 18 in molars, $25 \mathrm{DE}$ restorations were placed in premolars, 18 in molars, 28 TC restorations were placed in premolars, 13 in molars (Table 1). This distribution was not significant according to a $\chi^{2}$-test $(p=0.574)$. There was a certain over-representation of AD restorations in the group of three and more surface restorations (24) when compared to DE (14) and TC (14), $p=0.065$ according to the $\chi^{2}$-test.

\subsection{Restorative materials}

Because composite restoratives are generally marketed as a complete system, including the proprietary etching, primer and bonding products, the present study was performed using each composite with its proprietary adhesive system. Three composite restorative systems, of which two were ormocer-based (Admira/Admira Bond and Definite/Etch \& Prime 3.0) and one was bis-GMA-based (Tetric-Ceram/Syntac Sprint), were used in this study. Their composition is summarized in Table 2.

\subsection{Clinical procedure}

If necessary, local anaesthesia was administered. The cavity was opened (or the existing restoration was removed) using a pear-shaped diamond bur (Komet, 830L, Komet, Lemgo, Germany) on a high-speed air turbine. Rubber dam was placed either before the operative procedure or after opening the cavity according to the accessibility. Caries was removed by slow-speed metal burs and hand instruments, leaving discoloured but hard dentine at the cavity floor. Cavities were designed according the principles of minimal invasive dentistry. If the cavity extended for more than $2 \mathrm{~mm}$ into

Table 1 - Distribution of restorative systems among tooth types and quadrants

\begin{tabular}{|c|c|c|c|c|c|c|c|c|}
\hline \multirow[t]{2}{*}{ Restorative system } & \multicolumn{2}{|c|}{ Maxillary molars } & \multicolumn{2}{|c|}{$\begin{array}{l}\text { Mandibular } \\
\text { molars }\end{array}$} & \multicolumn{2}{|c|}{$\begin{array}{l}\text { Maxillary } \\
\text { premolars }\end{array}$} & \multicolumn{2}{|c|}{$\begin{array}{l}\text { Mandibular } \\
\text { premolars }\end{array}$} \\
\hline & Right & Left & Right & Left & Right & Left & Right & Left \\
\hline $\mathrm{AD}$ & 6 & 6 & 2 & 4 & 8 & 8 & 8 & 4 \\
\hline $\mathrm{DE}$ & 6 & 8 & 1 & 4 & 10 & 10 & 2 & 5 \\
\hline TC & 2 & 6 & 2 & 3 & 12 & 6 & 2 & 5 \\
\hline
\end{tabular}

AD: Admira/Admira Bond; DE: Definite/Etch \& Prime 3.0; TC: Tertic-Ceram/Syntac Sprint. 
Table 2 - Materials: restorative system, composition and manufacturer

\begin{tabular}{|c|c|c|}
\hline Restorative system & Composition & Manufacturer \\
\hline Admira & $\begin{array}{l}\text { Resin matrix: aromatic and aliphatic dimethacrylates, } \\
\text { methacrylate-functionalized polysiloxane } \\
\text { Inorganic filler: Ba-Al-glass ( } 56 \text { vol\%) } \\
\text { Photoinitiator: camphorquinone }\end{array}$ & VOCO, Cuxhaven, Germany \\
\hline $\begin{array}{l}\text { Admira Bond (two-step } \\
\text { etch-and-rinse) }\end{array}$ & $\begin{array}{l}\text { Etchant: } 36 \% \text { phosphoric acid } \\
\text { Adhesive: acetone, bonding ormocer, } \\
\text { dimethacrylates, initiators, stabilizer }\end{array}$ & \\
\hline Definite & $\begin{array}{l}\text { Resin matrix: methacrylate-functionalized } \\
\text { polysiloxane, bis-GMA, TEGDMA } \\
\text { Inorganic filler: Ba-glass, pyrogenic } \mathrm{SiO}_{2}(61 \mathrm{vol} \%) \\
\text { Photoinitiator: camphorquinone }\end{array}$ & $\begin{array}{l}\text { Degussa, Hanau, Germany (later taken over } \\
\text { by Dentsply, Konstanz, Germany) }\end{array}$ \\
\hline $\begin{array}{l}\text { Etch \& Prime } 3.0 \\
\text { (one-step self-etch) }\end{array}$ & $\begin{array}{l}\text { Catalyst: HEMA, pyrophosphate, initiators, stabilizer } \\
\text { Universal: HEMA, ethanol, deionized water, stabilizer }\end{array}$ & \\
\hline Tetric-Ceram & $\begin{array}{l}\text { Resin matrix: UDMA, bis-GMA, TEGDMA } \\
\text { Inorganic filler: } \mathrm{Ba} \text {-glass, } \mathrm{Ba}-\mathrm{Al} \text {-F-glass, } \mathrm{Al}_{2} \mathrm{O}_{3} \text {, } \\
\mathrm{YbF}_{3} \text {, pyrogenic } \mathrm{SiO}_{2} \text { ( } 60 \text { vol.\%) } \\
\text { Photoinitiator: camphorquinone }\end{array}$ & Ivoclar-Vivadent, Schaan, Liechtenstein \\
\hline $\begin{array}{l}\text { Syntac Sprint (two-step } \\
\text { etch-and-rinse) }\end{array}$ & $\begin{array}{l}\text { Etchant: } 37 \% \text { phosphoric acid } \\
\text { Adhesive: HEMA, deionized water, modified polyacrylic } \\
\text { acid, maleic acid, catalysts, stabilizers, fluoride }\end{array}$ & \\
\hline
\end{tabular}

bis-GMA: bisphenol A-glycidyl dimethacrylate; TEGDMA: triethyleneglycoldimethacrylate; UDMA: urethane dimethacrylate; HEMA: 2hydroxyethyl methacrylate.

the dentine, a glass-ionomer cement lining was applied at the pulpal wall (Ketac-Bond, 3MESPE, Seefeld, Germany). The facial and lingual margins in the proximal box were bevelled, while the preparation outline in the cervical margin was only bevelled when ending in enamel, otherwise a butt-joint was prepared. At the occlusal outline, a butt-joint preparation was left in order to minimize the surface exposed to occlusal load. All cavities were restored using a sectional metal matrix (Contact Matrix, Palodent, USA) fixed with a ring and wooden wedges. Cavities restored with Admira were etched by application of the proprietary etching gel to the enamel margins (15s) and then to the dentine (15s). Cavities were rinsed with air-water spray for $15 \mathrm{~s}$ and dried avoiding overdrying (maximal $10 \mathrm{~s}$, according to cavity size and geometry). Admira Bond was applied with a micro-brush and left for $30 \mathrm{~s}$, followed by gentle air-drying and polymerization for $30 \mathrm{~s}$. The adhesive procedure for DE was performed by applying freshly mixed one-step self-etch adhesive, Etch \& Prime 3.0 for $30 \mathrm{~s}$ to the cavity walls, followed by gentle air-drying and polymerization for $30 \mathrm{~s}$. The procedure for the Tetric-Ceram restorative included etching with the proprietary etching gel (enamel $15 \mathrm{~s}$, dentin $15 \mathrm{~s}$ ), rinsing with air/water spray for $15 \mathrm{~s}$, gentle airdrying and application of Syntac Sprint with a micro-brush. After $30 \mathrm{~s}$, the solvent was evaporated with a gentle air stream followed by polymerization for $30 \mathrm{~s}$. The restorative materials were applied following the multi-increment technique. AD and TC were dispensed from a syringe and transported to the cavity with a spatula, DE was applied from capsules with the proprietary dispenser. Between each increment ( $\max 2 \mathrm{~mm}$ ), polymerization was performed with an Astralis 5 (IvoclarVivadent, Schaan, Liechtenstein, tip diameter $8 \mathrm{~mm}$ ) halogen light-curing unit for $40 \mathrm{~s}$ (DE and TC) or $60 \mathrm{~s}$ (AD). The light output was measured using a hand-held curing radiometer (Demetron, Danbury CT, USA) and did not fall below
$400 \mathrm{~mW} \mathrm{~cm}^{-2}$. The light was directed perpendicular to the occlusal surface. No post-curing from buccal or lingual was performed after matrix removal. Then the rubber dam was removed and occlusion and articulation were checked and adjusted, followed by finishing with fine-grit diamond instruments (8862 and 862EF, Komet, Lemgo, Germany), Sof-lex discs (3MESPE, Seefeld, Germany) and rubber polishing instruments (Kenda Hybrid, Vaduz, Liechtenstein). All finishing procedures were performed under water cooling. The time allotted to the placement of the restoration was scheduled to take about $45 \mathrm{~min}$ and the procedure was chosen to approach daily clinical routine as much as possible. Since composite restorative materials undergo rapid turnover and changes in their formulation, to gain time three practitioners performed the study. The three practitioners participating in the study were given written instructions about the protocol, supplemented by a discussion prior to the start of the study. Several restorations were scored twice at the 3-year recall by all participating practitioners and data were analyzed using Cohen's kappa test. All practitioners had followed their dental education at the same university and prior to the study had participated in postgraduate courses concerning composite restoration techniques. Two of the practitioners (M.A. and F.K.) worked part-time in a private practice.

\subsection{Evaluation procedure}

The restorations were evaluated at baseline, 6, 12, 24 and 36 months according to a modification of the classical USPHS criteria (Köhler et al. ${ }^{7}$, details can be found in Table 3) and bitewing radiographs (except the 6 months recall). Clinical scoring was performed using a mirror, a Hu-Friedy CH3 (Hu-Friedy, Chicago, USA) probe for marginal scoring and anatomy and dental floss to check the contact points. Whenever possible, 


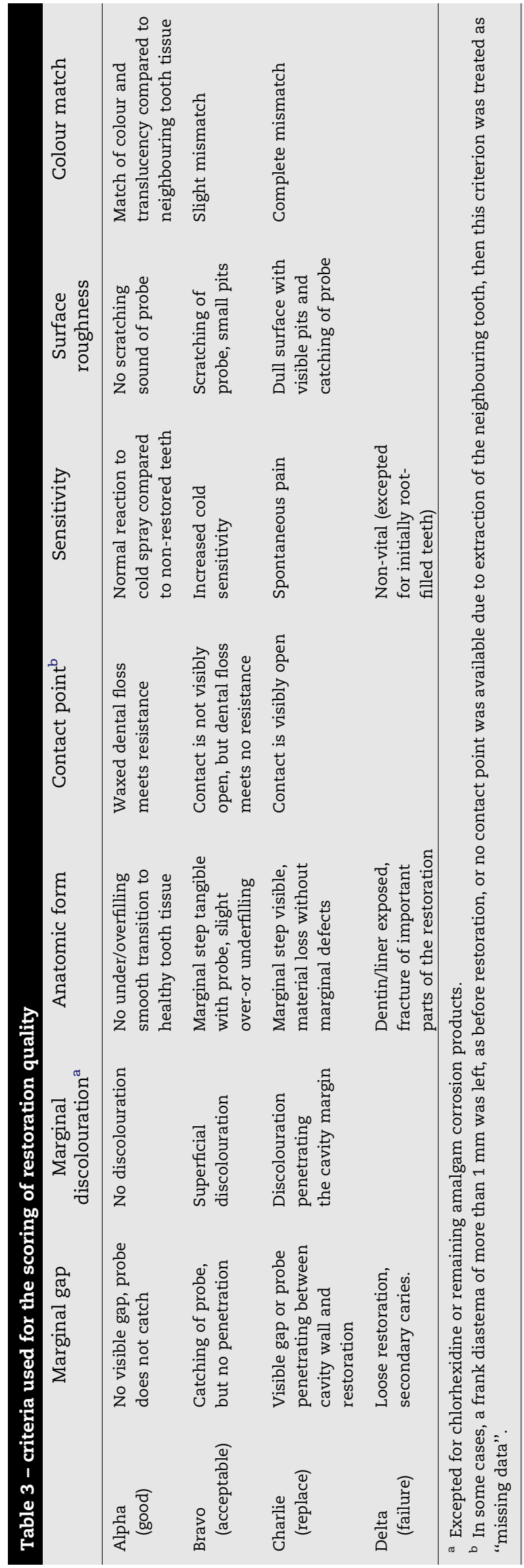

the restorations were not scored by the practitioner who had placed them. This necessitated, according to staff availability, that the baseline examination was performed several days after the placement of the last restoration. During the baseline and 6 month evaluation, the senior researcher (PB) was present either as evaluator or to take notes. This ensured a maximal equality of scoring criteria and training of the three evaluators (P.B., F.K. and M.A.). Bite-wing radiographs were taken using a Rinn beam aiming device for bite-wing exposure, Agfa Dentus no. 1 double exposure E-speed X-ray film (Heraeus-Kulzer, Hanau, Germany). Exposure was performed using a Gendex long-cone X-ray source at $10 \mathrm{~mA}, 75 \mathrm{kV}$ peak at an exposure time of $0.34 \mathrm{~s}$. Films were developed using a Dürr Periomat automatic processor (Dürr, Bietigheim-Bissingen, Germany).

Two practitioners (P.B. and M.A.) scored bite-wing radiographs on a negatoscope in consensus. Scores (good, acceptable, failure) were attributed for:

Marginal gaps on the cervical margin and cervical recurrent caries:

- good: continuous contour between tooth tissue and restoration, no visible interface along the cavity margins;

- acceptable: continuous contour, but small radiolucent line which can be attributed to radiolucent bonding, especially if "pooling" of bonding in the pulpo-cervical line angle was visible;

- failure: radiolucent discontinuity especially on the external margins spreading into dentine.

\section{Porosities:}

- good: no visible porosities;

- acceptable: small air inclusions $(<0.5 \mathrm{~mm})$ well inside the material;

- failure: larger air bubbles or small air bubbles on the outer contour of the restoration.

\section{Cervical under/overfilling:}

- good: continuity between root and filling surface;

- acceptable: slight impression of wedge into restoration surface, over/undercontour of less than $0.5 \mathrm{~mm}$;

- failure: important impression of wedge into restoration surface, over/undercontour exceeding $0.5 \mathrm{~mm}$.

\subsection{Statistical processing}

All data were entered in a SPSS database (SPSS Inc. Chicago, IL, USA). Comparison between different materials at the same time was performed with the Kruskall-Wallis test (K.W.) followed by a pairwise Mann-Whitney $U$-test if a $p$-value of $<0.05$ was reached. Comparison between the different recall examinations was calculated by a Friedman test followed by a paired Wilcoxon test. Furthermore, an analysis of variance was performed including size of restoration (number of restored surfaces), primary or secondary caries and operator. A cumulative failure score (failure for marginal integrity and/ or anatomy, radiography or vitality) was used to calculate and compare survival curves for the different materials using the 


\begin{tabular}{|c|c|c|c|c|c|c|c|c|c|c|c|c|c|c|c|c|c|c|c|c|}
\hline Recall time (months) & 0 & 6 & 12 & 24 & 36 & 0 & 6 & 12 & 24 & 36 & 0 & 6 & 12 & 24 & 36 & 0 & 6 & 12 & 24 & 36 \\
\hline Restorative system & \multicolumn{5}{|c|}{ Alpha } & \multicolumn{5}{|c|}{ Bravo } & \multicolumn{5}{|c|}{ Charlie } & \multicolumn{5}{|c|}{ Delta } \\
\hline \multicolumn{21}{|l|}{ Admira } \\
\hline Marginal gap & 42 & 38 & 37 & 31 & 14 & 2 & 3 & 3 & 8 & 7 & 0 & 1 & 2 & 1 & 3 & 0 & 0 & 0 & 1 & 2 \\
\hline Marginal discolouration & 39 & 35 & 36 & 28 & 15 & 5 & 6 & 5 & 12 & 9 & 0 & 1 & 0 & 0 & 1 & & & n.a & & \\
\hline Anatomic form & 27 & 28 & 28 & 28 & 16 & 17 & 13 & 11 & 11 & 6 & 0 & 0 & 1 & 1 & 3 & 1 & 1 & 1 & 0 & 2 \\
\hline Contact point & 36 & 35 & 31 & 30 & 16 & 6 & 5 & 8 & 8 & 6 & 1 & 1 & 0 & 2 & 3 & & & n.a. & & \\
\hline Sensitivity $^{\mathrm{a}}$ & 29 & 35 & 35 & 30 & 23 & 8 & 6 & 4 & 7 & 2 & 0 & 0 & 0 & 0 & 0 & 2 & 1 & 2 & 2 & 2 \\
\hline Surface roughness & 34 & 41 & 38 & 38 & 19 & 9 & 1 & 3 & 1 & 4 & 1 & 0 & 0 & 1 & 2 & & & n.a. & & \\
\hline Colour match & 27 & 25 & 30 & 24 & 12 & 17 & 15 & 10 & 15 & 17 & 1 & 3 & 2 & 2 & 2 & & & n.a. & & \\
\hline \multicolumn{21}{|l|}{ Definite } \\
\hline Marginal gap & 40 & 35 & 36 & 31 & 16 & 3 & 5 & 5 & 10 & 12 & 0 & 0 & 0 & 0 & 0 & 0 & 1 & 1 & 2 & 1 \\
\hline Marginal discolouration & 35 & 35 & 31 & 29 & 18 & 8 & 6 & 9 & 11 & 10 & 0 & 0 & 0 & 1 & 0 & & & n.a. & & \\
\hline Anatomic form & 27 & 26 & 24 & 24 & 19 & 16 & 14 & 13 & 15 & 10 & 0 & 0 & 0 & 0 & 1 & 0 & 1 & 1 & 2 & 2 \\
\hline Contact point & 35 & 34 & 28 & 27 & 19 & 5 & 5 & 9 & 10 & 10 & 1 & 0 & 1 & 2 & 1 & & & n.a. & & \\
\hline Sensitivity & 32 & 35 & 32 & 29 & 26 & 6 & 3 & 5 & 8 & 2 & 0 & 0 & 0 & 0 & 0 & 3 & 3 & 3 & 3 & 3 \\
\hline Surface roughness & 35 & 37 & 31 & 37 & 19 & 8 & 4 & 9 & 3 & 9 & 1 & 0 & 0 & 1 & 0 & & & n.a. & & \\
\hline Colour match & 10 & 12 & 10 & 7 & 4 & 26 & 25 & 22 & 26 & 20 & 8 & 5 & 9 & 9 & 11 & & & n.a. & & \\
\hline \multicolumn{21}{|l|}{ Tetric-Ceram } \\
\hline Marginal gap & 40 & 37 & 34 & 30 & 16 & 1 & 3 & 4 & 9 & 8 & 0 & 0 & 0 & 0 & 0 & 0 & 0 & 0 & 0 & 1 \\
\hline Marginal discolouration & 37 & 34 & 31 & 27 & 13 & 4 & 6 & 3 & 11 & 10 & 0 & 0 & 0 & 1 & 1 & & & n.a. & & \\
\hline Anatomic form & 35 & 37 & 28 & 23 & 17 & 6 & 2 & 8 & 15 & 7 & 0 & 1 & 2 & 1 & 1 & 0 & 0 & 0 & 0 & 1 \\
\hline Contact point & 33 & 30 & 28 & 27 & 17 & 6 & 8 & 8 & 8 & 7 & 0 & 0 & 0 & 2 & 1 & & & n.a. & & \\
\hline Sensitivity & 29 & 34 & 35 & 30 & 22 & 8 & 6 & 3 & 4 & 1 & 0 & 0 & 0 & 1 & 0 & 0 & 0 & 1 & 1 & 1 \\
\hline Surface roughness & 33 & 39 & 37 & 38 & 20 & 8 & 2 & 1 & 1 & 4 & 0 & 0 & 0 & 0 & 0 & & & n.a. & & \\
\hline Colour match & 16 & 21 & 24 & 22 & 12 & 26 & 20 & 14 & 17 & 17 & 0 & 0 & 1 & 1 & 3 & & & n.a. & & \\
\hline
\end{tabular}


Kaplan-Meyer survival function (Prism version 3.02, GraphPad Software, USA).

\section{Results}

In total, 135 restorations were present at baseline. Two patients failed to respond to all recall examinations, leaving 132 restorations for evaluation after 2 years and 79 after 3 years (26 AD, $28 \mathrm{DE}$ and $25 \mathrm{TC}$ ). One patient had all her restorations ( $1 \mathrm{AD}, 1 \mathrm{DE}$ and $2 \mathrm{TC}$ ) replaced in a private practice after 1 year for unclear reasons, and two (AD) restorations were replaced by a full crown.

The kappa test performed on the repeated evaluations resulted in values between 0.47 and $0.64(p<0.05)$ for interrater agreement, and 0.65 to $0.74(p<0.05)$ for intra-rater agreement.

The scores for the different materials are displayed in Table 4. An overview of the statistical tests is given in Table 5. Between baseline and the second and third year recall, all materials showed a significant $(p<0.005)$ deterioration of marginal quality (marginal gap and marginal staining). At all appointments (baseline and recall), no significant difference could be found between the three tested composites $\left(\chi^{2}\right.$ : $p>0.05$, Kruskal-Wallis (K.W.): $p>0.05$ ).

Evaluation of anatomic form showed that on baseline and after 6 months, Tetric-Ceram performed significantly better $(p<0.01)$ than both ormocer materials. However, between baseline and 2 years, TC experienced a significant loss of anatomy $(p<0.001)$ and after 3 years all materials performed comparably. Definite and Admira did not change significantly over the 3-year period. Two failures (1 AD and $1 \mathrm{DE}$ ) occurred in a patient with bruxism, in both cases a cusp next to the restoration fractured leading to its replacement.

Surface structure resulted in a significant $(p<0.05)$ smoothening of $\mathrm{AD}$ and TC after 6 months when compared to baseline. After year 1 , DE scored significantly rougher than TC $(p=0.018)$. There were no significant different scores between the materials at the other control appointments.

The quality of the contact point diminished slightly in $\mathrm{AD}$ $(p=0.046)$ and DE $(p=0.034)$ between baseline and 3 years. There was no significant difference between all materials at all appointments (K.W. $p>0.05$ ).

Definite showed the worst colour match, when compared to either AD or TC $(p<0.01)$ at all appointments. Between time 0 and 2 years, there was no significant change in colour match within one material $(p>0.05)$, after 3 years DE showed a significant quality loss $(p<0.05)$.

Pulp sensitivity was not seen in all but two cases. Neither between baseline and control appointments nor between the different materials, there were significant differences (Friedman, $p>0.05$, K.W., $p>0.05$ ). Two teeth with extensive restorations showed problems with pulpitis during the study, one (TC) had to undergo a root canal treatment after 6 months, in the other case (TC) the problem was solved by replacing the restoration.

The results of bite-wing radiograph evaluation are summarized in Fig. 1. Problems with exposure geometry or

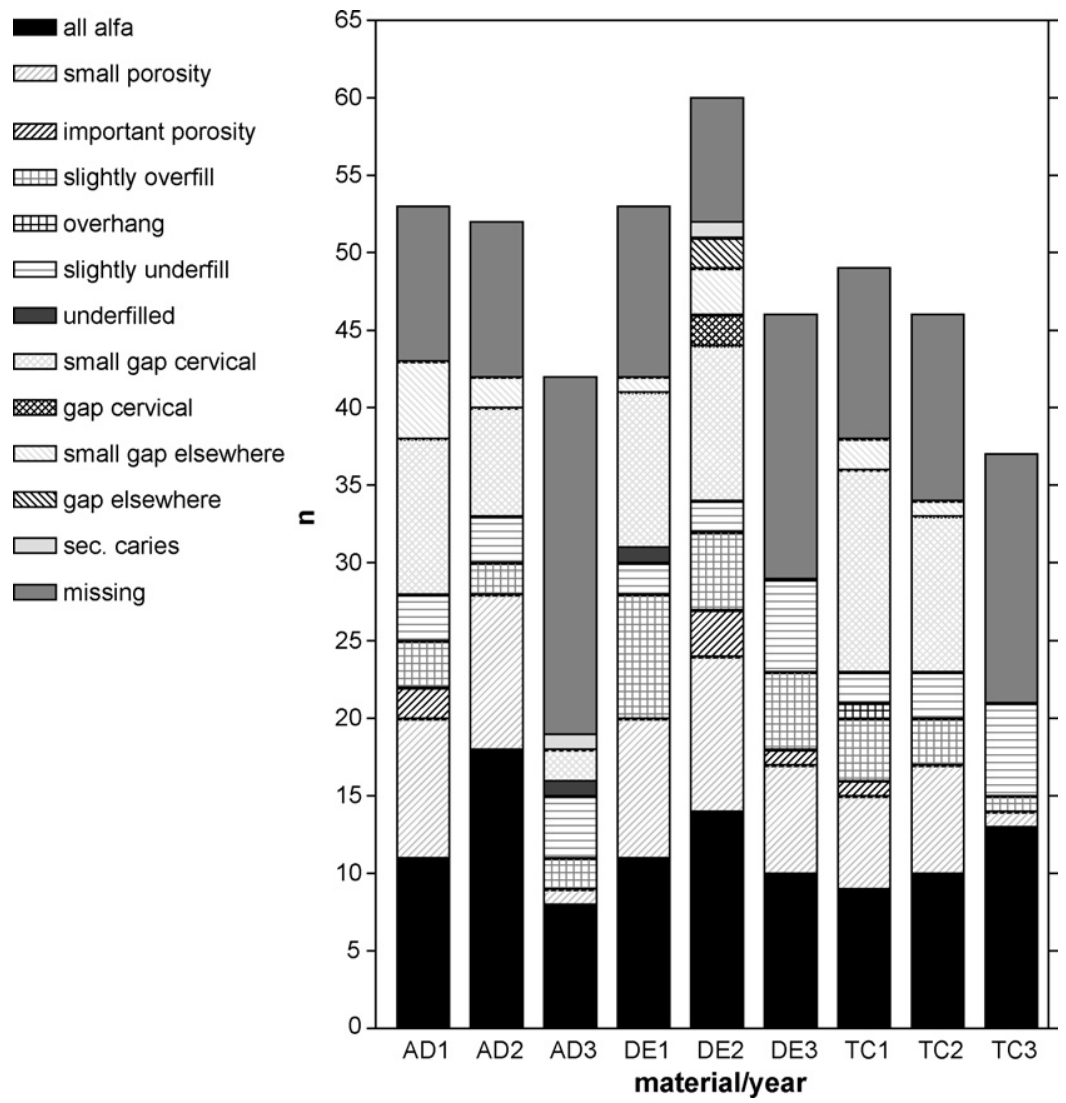

Fig. 1 - Scores attributed to bite-wing radiographs (AD: Admira, 1, after 1 year, 2 after 2 years; DE: Definite, TC: Tetric-Ceram). 
Table 5 - Overview of statistical tests

\begin{tabular}{|c|c|c|c|c|c|}
\hline Criterium & 0 months & 6 months & 12 months & 24 months & 36 months \\
\hline & \multicolumn{5}{|c|}{ Comparison between restorative systems at different recalls: ( $<$ worse than, $>$ better than) } \\
\hline Marginal gap & n.s. & n.s. & n.s. & n.s. & n.s. \\
\hline Marginal discolouration & n.s. & n.s. & n.s. & n.s. & n.s. \\
\hline Anatomic form & $\mathrm{TC}>\mathrm{AD}+\mathrm{DE}\left({ }^{*}\right)$ & $\mathrm{TC}>\mathrm{AD}+\mathrm{DE}\left({ }^{* *}\right)$ & n.s. & n.s. & n.s. \\
\hline Contact point & n.s. & n.s. & n.s. & n.s. & n.s. \\
\hline Sensitivity & n.s. & n.s. & n.s. & n.s. & n.s. \\
\hline Surface roughness & n.s. & n.s. & $\mathrm{DE}<\mathrm{TC}(*)$ & n.s. & n.s. \\
\hline Colour match & $\mathrm{DE}<\mathrm{AD}+\mathrm{TC}\left({ }^{*}\right)$ & $\mathrm{DE}<\mathrm{AD}+\mathrm{TC}\left({ }^{*}\right)$ & $\mathrm{DE}<\mathrm{AD}+\mathrm{TC}(* * *)$ & $\mathrm{DE}<\mathrm{AD}+\mathrm{TC}\left({ }^{* * *}\right)$ & $\mathrm{DE}<\mathrm{AD}+\mathrm{TC}\left({ }^{* *}\right)$ \\
\hline \multirow[t]{2}{*}{ Criterium } & & \multicolumn{4}{|c|}{ Comparison with initial situation (+: better, - : worse than initial) } \\
\hline & & 6 & 12 & 24 & 36 months \\
\hline Marginal gap & & n.s. & n.s. & $\begin{array}{l}\mathrm{AD}-\left({ }^{*}\right) ; \mathrm{DE}-\left(^{* *}\right) ; \\
\mathrm{TC}-\left({ }^{* *}\right)\end{array}$ & $\begin{array}{l}\mathrm{AD}-\left({ }^{* *}\right) ; \mathrm{DE}-\left({ }^{* *}\right) ; \\
\mathrm{TC}-\left({ }^{* *}\right)\end{array}$ \\
\hline Marginal discolouration & & n.s. & n.s. & $\begin{array}{l}\mathrm{AD}-\left({ }^{*}\right) ; \mathrm{DE}-\left(^{*}\right) ; \\
\mathrm{TC}-\left({ }^{* *}\right)\end{array}$ & $\begin{array}{l}\mathrm{AD}-\left(^{* *}\right) ; \mathrm{DE}-\left({ }^{* *}\right) ; \\
\mathrm{TC}-\left({ }^{* *}\right)\end{array}$ \\
\hline Anatomic form & & n.s. & $\mathrm{TC}-\left(^{*}\right)$ & $\mathrm{TC}-\left(^{* *}\right)$ & $\mathrm{TC}-\left(^{*}\right)$ \\
\hline Contact point & & n.s. & n.s. & n.s. & n.s. \\
\hline Sensitivity & & n.s. & n.s. & n.s. & n.s. \\
\hline Surface roughness & & $\mathrm{AD}+\left({ }^{* *}\right), \mathrm{TC}+\left(^{* *}\right)$ & $\mathrm{AD}+\left(^{*}\right) ; \mathrm{TC}+\left(^{*}\right)$ & n.s. & n.s. \\
\hline Colour match & & n.s. & n.s. & n.s. & $\mathrm{DE}-\left(^{*}\right)$ \\
\hline
\end{tabular}

AD: Admira/Admira Bond; DE: Definite/Etch \& Prime 3.0; TC: Tetric-Ceram/Syntac Sprint. $\left({ }^{*}\right): p<0.05,\left({ }^{*}\right): p<0.005,\left({ }^{* *}\right): p<0.001$

processing errors resulted in some data loss. Between materials, no significant differences could be found for all criteria (K.W., $p>0.05$ ).

Small gaps at the gingival surface (bonding excess) and porosities were the most frequently occurring problems.

In all materials, some failures occurred. The log-rank analysis of the different survival curves (Fig. 2) showed no significant difference $(p=0.42)$ between the three types of composite. An annual failure rate of $3 \%$ could be calculated for $\mathrm{AD}, 3 \%$ for $\mathrm{DE}$ and $2 \%$ for $\mathrm{TC}$.

The results of the analysis of variance are presented in Table 6. Cavity size significantly contributed to the performance of all restorative systems, especially for contact point, marginal gap and anatomic form. The operator contributed sometimes to the performance of the restoration but not in a systematic way and never in the initial evaluation.

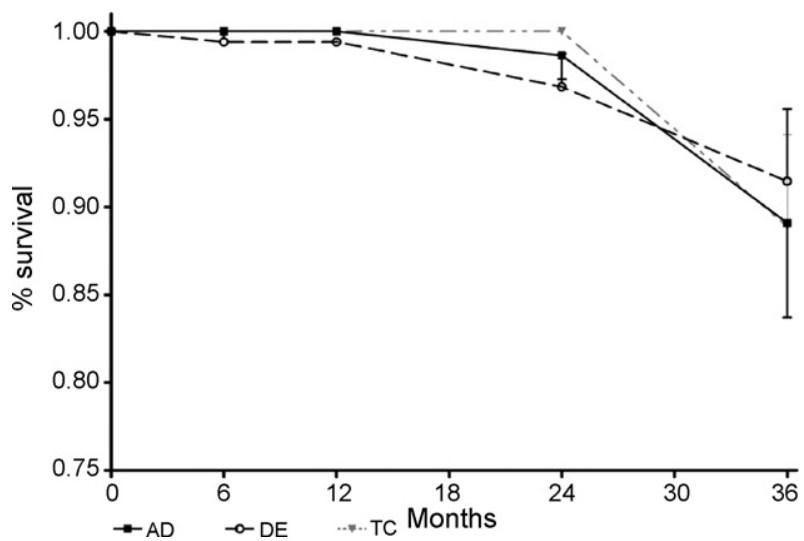

Fig. 2 - survival curves ( \pm S.E.M.) for Admira (AD), Definite (DE) and Tetric-Ceram (TC).

\section{Discussion}

In the course of the study, the restorations went through some changes. The marginal quality first improved somewhat, probably due to wear of excess material at the margins. ${ }^{8}$ Thereafter, degradation phenomena were observed, such as weaker proximal contact areas, most probably due to wear. ${ }^{9}$ Marginal fractures were observed from the 1-year control onwards. In our study, the butt-joint occlusal outline, instead of a bevelled preparation outline in combination with the extensive nature of the restorations, could be an explanation for the formation of marginal fractures. Degradation of marginal quality has been reported for DE in a 1-year clinical evaluation by Oberländer et al., ${ }^{10}$ which may be explained by a shorter time schedule and use of cotton-roll insulation in contrast to the use of rubber dam in the current study. Post-operative hypersensitivity was not problematic in this study, only one restoration had to be replaced. The highly significant contribution of cavity size to the variable sensitivity in the ANOVA could be explained by a higher number of teeth being non-vital at the start of the study and requiring more extensive restorations. In contrast to the findings of Lundin and Rasmusson, ${ }^{11}$ who reported a frequent occurrence of post-operative sensitivity, restorations in our study were placed using rubber dam insulation, which might have contributed to the difference in results. Colour match was satisfactory for $\mathrm{AD}$ and $\mathrm{TC}$, but substandard in DE for which post-curing colour differences were described. ${ }^{12}$ The authors speculated that a higher fraction of aromatic amines in the photoinitiator system used may be the reason for this phenomenon. The radiolucent line observed in the bite-wing radiographs could have been the consequence of bonding "pooling", described as typical for ormocer materials. ${ }^{5}$

It is to be noted that in this study rather extensive restorations were placed. This fact was shown to have a 
Table 6 - Results of the one-way ANOVA performed on different variables with type of restorative system, number of surfaces, primary caries or restoration replacement and operator as independent variables

\begin{tabular}{|c|c|c|c|c|c|}
\hline $\begin{array}{l}\text { Dependent } \\
\text { variable }\end{array}$ & $\begin{array}{l}\text { Recall period } \\
\text { (months) }\end{array}$ & $\begin{array}{l}\text { Restorative system } \\
\text { (AD/DE/TC) }\end{array}$ & $\begin{array}{c}\text { Number of } \\
\text { surfaces }(2-4)\end{array}$ & $\begin{array}{c}\text { Primary caries/ } \\
\text { re-placement }\end{array}$ & Operator (MA, PB, FK) \\
\hline \multirow[t]{5}{*}{ Marginal gap } & 0 & n.s. & n.s. & n.s. & n.s. \\
\hline & 6 & n.s. & 0.032 & n.s. & 0.001 \\
\hline & 12 & n.s. & n.s. & n.s. & 0.001 \\
\hline & 24 & n.s. & n.s. & n.s. & n.s. \\
\hline & 36 & n.s. & 0.025 & n.s. & n.s. \\
\hline \multirow[t]{5}{*}{ Marginal discolouration } & 0 & n.s. & n.s. & n.s. & n.s. \\
\hline & 6 & n.s. & n.s. & n.s. & 0.012 \\
\hline & 12 & n.s. & n.s. & n.s. & n.s. \\
\hline & 24 & n.s. & 0.012 & n.s. & n.s. \\
\hline & 36 & n.s. & 0.013 & n.s. & n.s. \\
\hline \multirow[t]{5}{*}{ Anatomic form } & 0 & n.s. & 0.023 & n.s. & n.s. \\
\hline & 6 & n.s. & n.s. & n.s. & n.s. \\
\hline & 12 & n.s. & n.s. & n.s. & n.s. \\
\hline & 24 & n.s. & n.s. & n.s. & n.s. \\
\hline & 36 & n.s. & 0.026 & n.s. & n.s. \\
\hline \multirow[t]{5}{*}{ Contact point } & 0 & n.s. & 0.019 & n.s. & n.s. \\
\hline & 6 & n.s. & 0.021 & n.s. & 0.053 \\
\hline & 12 & n.s. & 0.004 & n.s. & 0.019 \\
\hline & 24 & n.s. & $<0.001$ & n.s. & n.s. \\
\hline & 36 & n.s. & $<0.001$ & n.s. & n.s. \\
\hline \multirow[t]{5}{*}{ Sensitivity } & 0 & n.s. & $<0.001$ & n.s. & n.s. \\
\hline & 6 & n.s. & $<0.001$ & n.s. & n.s. \\
\hline & 12 & n.s. & $<0.001$ & n.s. & n.s. \\
\hline & 24 & n.s. & $<0.001$ & n.s. & n.s. \\
\hline & 36 & n.s. & $<0.001$ & n.s. & n.s. \\
\hline \multirow[t]{5}{*}{ Surface roughness } & 0 & n.s. & n.s. & n.s. & n.s. \\
\hline & 6 & 0.041 & n.s. & 0.014 & n.s. \\
\hline & 12 & 0.018 & n.s. & n.s. & n.s. \\
\hline & 24 & n.s. & n.s. & 0.039 & 0.019 \\
\hline & 36 & n.s. & n.s. & n.s. & n.s. \\
\hline \multirow[t]{5}{*}{ Colour match } & 0 & $<0.001$ & 0.043 & n.s. & n.s. \\
\hline & 6 & $<0.001$ & n.s. & n.s. & n.s. \\
\hline & 12 & $<0.001$ & n.s. & n.s. & n.s. \\
\hline & 24 & $<0.001$ & n.s. & n.s. & n.s. \\
\hline & 36 & $<0.001$ & n.s. & n.s. & n.s. \\
\hline
\end{tabular}

Significant contribution of these variables ( $p$-value if $<0.05$, otherwise n.s.) are given per recall (in months).

negative effect on the quality of the restorations after exposure to the oral environment. In these cases extensive amalgam restorations were shown to perform better. ${ }^{13}$ Also, tooth-coloured ceramic inlays were shown to function satisfactorily over time, ${ }^{14}$ but the procedure and cost preclude, at least for this moment, a general application in clinical practice.

New developments in composite technology have shown a mitigated success in clinical studies. In the past some materials marketed with a claim of easier handling or "amalgam-like" clinical technique have been shown to not withstand clinical testing. ${ }^{15,16}$

The ormocer materials in the present study, however, were found to be comparable but not superior to a modern smallparticle hybrid composite. Therefore, we could reject the hypothesis that differences in the composition of restorative systems had an influence on the clinical outcome. Some reasons for this may be the fact that material properties are not the only factor in success or failure. In a meta-analysis,
Leloup et al. ${ }^{17}$ showed that more factors contribute to adhesive force between composite and dentine, such as origin and quality of the tooth's hard tissues or diameter and direction of dentinal tubuli. Clinical and laboratory research revealed the superiority of three-step, ethanol-water-based etch-and-rinse adhesives. ${ }^{18}$ Reports were published about an inferior performance of one-step self-etch- and two-step etch-and-rinse adhesives, like Etch \& Prime 3.0 and Admira Bond with respect to micro leakage and bond strength ${ }^{10}$ and in clinical conditions. ${ }^{18,19}$ However, these findings could not (yet) be confirmed in the present study. The present study showed, after a relatively short evaluation period of 3 years, no significant differences between the three bonding systems with respect to marginal degradation. Adhesive failures were not frequent in this study; only one restoration (TC) was lost due to debonding between the 24-month and 36-month recall. Adhesive failures were more frequently encountered in cervical restorations where the cavity preparation is generally non-retentive. ${ }^{20}$ In class II cavities, the influence of the 
adhesive system used seemed not to influence the long-term results to a significant extent. ${ }^{21}$ This could also be found in the present data. Ormocers have a different matrix but share similar filler particles and a coupling mechanism with conventional resin composites. In laboratory studies, ormocer materials were found to be subject to marginal ridge fracture ${ }^{22}$ but their abrasion resistance was similar to conventional microhybrid composites. ${ }^{23}$

When compared to other clinical studies in the domain of composite resins (for a survey se ${ }^{24}$ ), the present results were in the range of other studies. However, comparison of clinical studies is not a straightforward affair. Criteria used for evaluation are all based on the work by Ryge and Snyder ${ }^{25}$ but vary widely in the way the scores are attributed. According to Hayashi et $\mathrm{al}^{26}$ further standardization of methods in clinical studies would be necessary in order to obtain a real comparability of their results.

Furthermore, the authors were somewhat frustrated with the fact that clinical studies do not always contribute efficiently to the establishing of "evidenced-based" dental medicine. By the time this study was terminated, two of the tested materials had either undergone modifications in their formulation (as in the case of Tetric-Ceram) or were no longer available (as in the case of Definite). For the sake of practitioners and patients, we plead for a controlled clinical study to be performed preceding market introduction.

\section{Conclusions}

In conclusion, it can be stated that in occlusal stress-bearing cavities the ormocer-based composite materials tested performed comparably to the conventional microhybrid bisGMA-based composite, with the exception that DE had a poor colour match.

\section{Acknowledgements}

This study was funded by VOCO, Cuxhaven, Germany.

\section{R E FER E N C ES}

1. Collins CJ, Bryant RW, Hodge KLV. A clinical evaluation of posterior composite resin restorations: 8-year findings. Journal of Dentistry 1998;26:311-7.

2. Rosin M, Steffen H, Konschake C, Greese U, Teichmann D, Hartmann A, et al. One-year evaluation of an Ormocer restorative - a multipractice clinical trial. Clinical Oral Investigations 2003;7:20-6.

3. Bouillaguet S, Shaw L, Gonzalez L, Wataha JC, Krejci I. Longterm cytotoxicity of resin-based dental restorative materials. Journal of Oral Rehabilitation 2002;29:7-13.

4. Willershausen B, Schafer D, Pistorius A, Schulze R, Mann W. Influence of resin-based restoration materials on cytotoxicity in gingival fibroblasts. European Journal of Medical Research 1999;4:149-55.

5. Kournetas N, Chakmakchi M, Kakaboura A, Rahiotis C, GeisGerstorfer J. Marginal and internal adaptation of class II ormocer and hybrid resin composite restorations before and after lead cycling. Clinical Oral Investigations 2004;8:123-9.
6. Lopes LG, Cefaly DFG, Franco EB, Mondelli RFL, Lauris JRP, Navarro MFL. Clinical evaluation of two "packable" posterior composite resins: two-year results. Clinical Oral Investigations 2003;7:123-8.

7. Köhler B, Rasmusson CG, Odman P. A five-year clinical evaluation of class II composite resin restorations. Journal of Dentistry 2000;28:111-6.

8. Pesun IJ, Olsen AK, Hodges JS, Anderson GC. In vivo evaluation of the surface of posterior resin composite restorations: a pilot study. The Journal of Prosthetic Dentistry 2000;84:353-9.

9. Prakki A, Cilli R, Chalup Saad JO, Rodrigues JR. Clinical evaluation of proximal contacts of class II esthetic direct restorations. Quintessence International 2004;35:785-9.

10. Oberländer H, Hiller KA, Thonemann B, Schmalz G. Clinical evaluation of packable composite resins in class-II restorations. Clinical Oral Investigations 2001;5:102-7.

11. Lundin SA, Rasmusson CG. Clinical evaluation of a resin composite and bonding agent in class I and II restorations: 2-year results. Quintessence International 2004;35:758-62.

12. Janda R, Roulet JF, Kaminsky M, Steffin G, Latta M. Color stability of resin matrix restorative materials as a function of the method of light activation. European Journal of Oral Sciences 2004;112:280-5.

13. Plasmans PJ, Creugers NH, Mulders J. Long-term survival of extensive amalgam restorations. Journal of Dental Research 1998;77:453-60.

14. Schulte AG, Vöckler A, Reinhardt R. Longevity of ceramic inlays and onlays luted with a solely light-curing composite resin. Journal of Dentistry 2005;33:433-42.

15. Ernst CP, Martin M, Stuff S, Willershausen B. Clinical performance of a packable resin composite for posterior teeth after 3 years. Clinical Oral Investigations 2001;5: 148-55.

16. Merte I, Schneider H, Merte K. Ist es notwendig, eingeführte Füllungsmaterialien klinisch-experimentell zu bewerten? Schweizer Monatsschrift für Zahnmedizin 2004;114:1124-31.

17. Leloup G, D'Hoore W, Bouter D, Degrange M, Vreven J. Metaanalytical review of factors involved in dentin adherence. Journal of Dental Research 2001;80:1605-14.

18. De Munck J, Van Landuyt K, Peumans M, Poitevin A, Lambrechts P, Braem M, Van Meerbeek B. A critical review of the durability of adhesion to tooth tissue: methods and results. Journal of Dental Research 2005;84:118-32.

19. Peumans M, Kanumilli P, De Munck J, Van Landuyt K, Lambrechts P, Van Meerbeek B. Clinical effectiveness of contemporary adhesives: a systematic review of current clinical trials. Dental Materials 2005;21:864-81.

20. Aw TC, Lepe X, Johnson GH, Mancl LA. A three-year clinical evaluation of two-bottle versus one-bottle dentin adhesives. Journal of the American Dental Association 2005;136:311-22.

21. Brunthaler A, König F, Lucas T, Sperr W, Schedle A. Longevity of direct resin composite restorations in posterior teeth. Clinical Oral Investigations 2003;7:63-70.

22. Görücü J, Özgünaltay G. Fracture strength of class II slot cavities restored with polymerizable restorative materials. Polymers for Advanced Technologies 2003;14:586-91.

23. Yap AUJ, Tan $\mathrm{CH}$, Chung SM. Wear behavior of new composite restoratives. Operative Dentistry 2004;29: 269-74.

24. Manhart J, Garcia-Godoy F, Hickel R. Direct posterior restorations: clinical results and new developments. Dental Clinics of North America 2002;46:303-39.

25. Ryge G, Snyder M. Evaluating the clinical quality of restorations. Journal of the American Dental Association 1973;87:369-77.

26. Hayashi M, Wilson NHF, Watts DC. Quality of marginal adaptation evaluation of posterior composites in clinical trials. Journal of Dental Research 2003;82:59-63. 